\title{
Superconducting Gravimeter Calibration by Colocated Gravity Observations: Results from GWR C025
}

\author{
Bruno Meurers \\ Department of Meteorology and Geophysics, University of Vienna, Althanstrasse 19, A-1090 Wien, Austria \\ Correspondence should be addressed to Bruno Meurers, bruno.meurers@univie.ac.at
}

Received 23 March 2012; Accepted 6 June 2012

Academic Editor: Jose Arnoso

Copyright () 2012 Bruno Meurers. This is an open access article distributed under the Creative Commons Attribution License, which permits unrestricted use, distribution, and reproduction in any medium, provided the original work is properly cited.

In autumn 2007 the superconducting gravimeter GWR C025 was transferred from Vienna (VI) to the new Conrad observatory (CO) $60 \mathrm{~km} \mathrm{SW}$ of Vienna. It is one of few instruments which were operated at different stations. This aspect motivated a reanalysis of all calibration experiments at VI and CO, focused on drift and noise effects. Considering the drift even of absolute gravimeters in a common adjustment reduces the root mean square error of the averaged calibration factor essentially. Also spring type gravimeters have some potential to contribute to the SG calibration factor determination. The calibration factor of GWR C025 did not significantly change during the transfer from VI to CO. The final calibration factor is calculated as weighted average over in total 9 JILAg and FG5 experiments with an accuracy of better than $\pm 0.5 \%$. The calibration factor is temporarily stable with maximum variation less than $\pm 0.1 \%$. Based on these results the gravity time series of VI and CO have been analyzed. The respective amplitude factors for $\mathrm{O}_{1}, \mathrm{~K}_{1}$, and $\mathrm{M}_{2}$ agree almost perfectly at both stations after correcting for ocean loading effects. The maximum deviation from the numbers provided by the nonhydrostatic-body-tide models DDW and MAT01 is $0.8 \%$.

\section{Introduction}

Currently, the superconducting gravimeter (SG) is the most precise instrument for investigating temporal gravity variations both in the time and the frequency domain. SGs exhibit an extremely small instrumental drift that can be modeled by either a linear or exponential function of time [1]. The superconducting gravimeter GWR C025 has been operating since 1995. For more than 12 years it was installed in an underground laboratory in Vienna (Austria) and moved to the new Conrad observatory (CO) $60 \mathrm{~km} \mathrm{SW}$ of Vienna (VI) in autumn 2007 (Figure 1). Both stations are located at the NE margin of the Eastern Alps. VI is situated at the transition from the Eastern Alps to the Vienna Basin at about $190 \mathrm{~m}$ altitude, while CO is located within the mountains at $1045 \mathrm{~m}$. The SG sphere could be kept levitated during transport. Consequently only minor readjustment measures were required, among others because of the gravity difference between both sites.

The gravity time series in CO currently extends over more than 4 years and allows now safely comparing the tidal analysis results for $\mathrm{VI}$ and $\mathrm{CO}$ as well as validating the most recent body-tide models $[2,3]$. The accuracy of gravimeter calibration is still a limiting factor for modern geodynamical studies based on gravity time series. In particular, validating different body tide models requires an accuracy of better than $1 \%$. From this viewpoint it is important to know the temporal stability of the calibration factor and the accuracy achieved under the given site noise conditions. The high site noise level in VI was one of the major problems with the SG response function determination. Therefore, big efforts have been done in order to clarify this question.

Presently, the most common method of SG calibration is based on colocated gravity observation by using absolute gravimeters (AG) [4]. In the time domain, the 1\%o accuracy level can be achieved by monitoring side by side during at least 5 to 7 days $[5,6]$. The calibration result does not depend on the specific AG used [7]. Actually, the calibration accuracy of SGs operating in the framework of GGP varies between a few \%o [8]. Taking a high number of calibration experiments into account, the error level can be reduced well below $1 \%$ o (e.g., $[9,10])$. Recently, [11] studied the performance of 


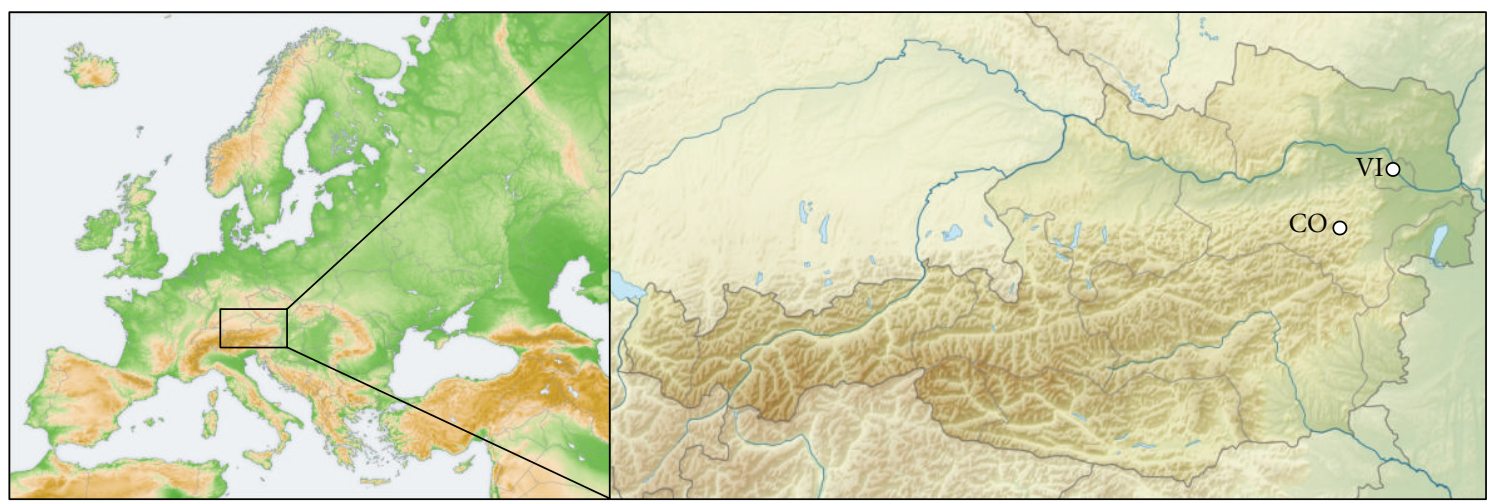

Figure 1: Location of SG sites in Vienna (VI: $48.2489^{\circ} \mathrm{N}, 16.3565^{\circ} \mathrm{E}, 192.74 \mathrm{~m}$ a.s.l.) and Conrad observatory $\left(\mathrm{CO}: 47.9283^{\circ} \mathrm{N}, 15.8598^{\circ} \mathrm{E}\right.$, $1044.12 \mathrm{~m}$ a.s.l.) (maps modified after http://commons.wikimedia.org/wiki/Category:Maps).

spring gravimeters used in the calibration experiment instead of an AG. Experiments for calibrating a LCR gravimeter by colocated SG observations have been reported by [12].

The calibration method relies on the basic assumption, that observation errors follow a Gaussian distribution, and that both the SG and AG sensor experience exactly the same gravity variation. Actually, this assumption is never perfectly true, as the signal composition of both sensors differs due to following reasons (e.g., [16]):

(1) instrumental noise,

(2) ground noise response,

(3) spatial separation of both sensors,

(4) transfer function introducing different time lags,

(5) preprocessing filter response,

(6) response on air pressure variations (e.g., non-compensated Archimedean forces in spring gravimeters),

(7) instrumental drift.

Kroner [17] reports on noticeable differences between Newtonian mass transport signals observed by the sensors of a dual sphere SG at Moxa. Similarly to Moxa, VI and CO can be regarded as underground stations with respect to local hydrology. Of course, the spatial separation of the sensors involved in the experiments in VI and CO is much larger than that of dual sphere SG sensors (Table 1). For estimating the effects expected at CO and VI, the gravitational effect of a water mass layer (e.g., due to rain) spread over the terrain surface has been estimated based on terrain models with high spatial resolution [18]. Table 1 presents the differences $\Delta g$ between the gravity signals at the respective sensor positions caused by $1 \mathrm{~cm}$ rain fall. At CO, sensors involved in the calibration experiments would experience a signal close to $4 \mathrm{nms}^{-2}$, but a maximum difference of $0.05 \mathrm{nms}^{-2}$ only in this scenario.

A systematic error arises when one or both sensors are influenced by instrumental drift [4]. Synthetic studies show that the calibration factor is systematically affected in those cases and strongly depends on the number of data pairs used in the regression analysis [16]. Typically, AG drift rates
TABLe 1: Spatial separation of the SG and colocated gravimeter sensors. $\Delta g$ is the difference between the Newtonian effects at the two sensor positions caused by $1 \mathrm{~cm}$ rain fall.

\begin{tabular}{ccccc}
\hline & & \multicolumn{2}{c}{ Sensor separation $(\mathrm{m})$} & \multirow{2}{*}{ Horizontal } \\
& & Vertical & $\Delta\left(\mathrm{nms}^{-2}\right)$ \\
\hline \multirow{3}{*}{ VI } & FG5 & 2.1 & 0.98 & 0.186 \\
& JILAg & 2.1 & 0.68 & 0.139 \\
& CG5 & 1.2 & -0.05 & 0.098 \\
\hline \multirow{4}{*}{ CO } & FG5 & 3.4 & 0.98 & 0.051 \\
& JILAg & 3.4 & 0.68 & 0.050 \\
& CG5 & 1.4 & -0.05 & 0.014 \\
\hline
\end{tabular}

are small and therefore are often neglected. However, at least the linear part of the instrumental AG drift has been taken into account in several SG calibration experiments (e.g., $[4,19,20])$. This paper addresses again the role of instrumental drift in calibration experiments based both on AGs and spring gravimeters and how the calibration results improve if the drift is considered even for AGs.

A performance study by [11] comes to the conclusion, that spring gravimeters cannot be used as stable reference for SG calibration. They compared different spring gravimeters like Scintrex Ltd. Autograv CG3 M and CG5 and MicrogLaCoste gPhone. Based on several experiments performed with a conventional Scintrex Autograv CG5 gravimeter, this problem is revisited in this paper. The question whether spring gravimeters can reliably support the calibration of SGs is discussed particularly under the aspect of drift determination. Finally, all results achieved so far for the SG GWR C025 are discussed.

\section{Calibration}

For calibration both different AGs and a well-calibrated Scintrex Autograv CG5 have been used. The calibration factor is calculated by linear adjustment of the gravity data acquired by the SG and the gravimeter used as reference (either the AG or the spring gravimeter). Acquisition and processing procedures are described in the following chapter. 
2.1. Data Acquisition and Processing. The raw 1s SG data is filtered by convolution with the GGP filter g1s $1 \mathrm{~m}$ (http://www.eas.slu.edu/GGP/ggpfilters.html) and resampled to $1 \mathrm{~s}$ data. The filter gain is equal to 1 within tidal frequencies including the quarter-diurnal band, about 0.9986 at periods of $10 \mathrm{~min}$ and rapidly decreases towards shorter periods $\left(1.8 \times 10^{-7}\right.$ at Nyquist frequency). However, gravity signals at these frequencies exhibit small amplitudes compared to the tides. For example, the amplitude of gravitational effects due to short term (10 $\mathrm{min})$ atmospheric processes is in the order of $1 \mathrm{nms}^{-2}$.

2.2. SG/AG Comparison. Three methods are applied in this study. In the first approach, each single AG drop is used. The corresponding SG data is extracted from the filtered 1s SG time series. The SG time lag is taken into account. Outliers are removed by applying either the $3 \sigma$-criterion or the modified $Z$-score method [21] on the AG residuals, separately for each AG drop set. The final data set consists of the SG-AG data pairs, their acquisition time and the standard deviation which is assumed to be identical with the standard deviation of the AG drop set a specific data pair originates from. Because the noise of the filtered SG data is much smaller than the AG drop-to-drop scatter, the SG data is assumed to be error-free in the adjustment process.

An alternate procedure, proposed for example, by [10], uses the AG drop set average instead of single drops. Because each AG drop set result represents the gravity averaged over the set interval (typically up to $60 \mathrm{~min}$ ), in this study the mean of the filtered SG data over the same interval is calculated instead of extracting just the SG data at the central time of the AG set. The number of data pairs now equals to the number of AG drop sets and thus is very small compared to the first method.

This method is slightly changed in a third procedure. Both SG and AG data is averaged by applying a moving window. The window length corresponds to the duration of one AG drop set. Then the standard deviation of the AG residuals within each window is determined. Like in the second method, the scatter of the averaged gravity is drastically reduced compared with the drop-to-drop scatter, but the number of data pairs entering the adjustment remains comparable with that of the first method.

2.3. SG/Spring Meter Comparison. In this study, a commercial Scintrex CG5 Autograv has been used (SN 40236). This instrument has been carefully calibrated twice a year on the Hochkar calibration line (HCL). The latter is located within the Northern Calcareous Alps of Austria and covers a gravity difference of $1980 \mu \mathrm{ms}^{-2}$ [22]. Short distances provide rapid access to in total four stations established along an Alpine road. Consequently, the gravimeter drift can be accurately determined as one cycle including all stations is completed within less than 2 hours. The gravity at all stations has been derived from absolute gravimeter observations. Absolute gravity measurements repeated in 1995 as well as regular relative gravity measurements in the past decades proved the HCL calibration line to be very stable and well suited for scale factor determination of relative gravimeters with high accuracy [23]. Due to the large gravity range, environmental gravity effects do not affect the calibration result severely. HCL is a vertical calibration line covering an elevation interval of about $950 \mathrm{~m}$. Thus systematic errors caused by buoyancy effects may occur in case of seal failure. However, this is not expected for the CG5, because the sensor unit is protected from ambient temperature and atmospheric pressure changes by sealing the sensor in a temperature stabilized vacuum chamber [24].

Repeated observations on HCL show that the CG5 scale factor varies linearly with time and decreased by $0.5 \%$ within 3.5 years (Figure 2). Therefore, determining the temporal CG5 scale factor variations on a regular base is mandatory. Fortunately this can be done on a high-accuracy level close to $0.05 \%$.

The Scintrex Autograv CG5 samples both gravity and tilt data with $6 \mathrm{~Hz}$ during a selectable time interval. The final gravity reading corresponds to the average over this interval (typically 1 or $2 \mathrm{~min}$ ), automatically corrected for tilt effects. The filtered 1s SG data is extracted and averaged over the same period. Optionally the CG5 readings can also be corrected for the tides. However, the CG5 acquisition software stores all results with a limited resolution of $10 \mathrm{nms}^{-2}$. Round off errors are produced later on, when the tides are restored, and affect the calibration result systematically. Therefore, this option is not recommendable for SG calibration. In this study, gravity measurements were performed in the autorepeat mode with 2 min duration during a few months.

2.4. Adjustment Procedure. Calibration factor and drift function are determined in a common adjustment process as proposed by, for example, $[4,12]$. For that purpose, the following scheme is implemented. Let $g$ be the true gravity signal, $g_{A G}$ the AG observation, $\tilde{g}_{S G}$ the uncalibrated SG signal, $d_{\mathrm{AG}}$ and $d_{\mathrm{SG}}$ the instrumental drift of the AG and SG respectively, and $a_{0}$ the calibration factor, then

$$
\begin{aligned}
& a_{0} \cdot \tilde{g}_{\mathrm{SG}}(t)=g(t)+d_{\mathrm{SG}}(t), \\
& g_{\mathrm{AG}}(t)=g(t)+d_{\mathrm{AG}}(t)=a_{0} \cdot \tilde{g}_{\mathrm{SG}}(t)+d_{\mathrm{AG}}(t)-d_{\mathrm{SG}}(t) .
\end{aligned}
$$

The differential drift signal on the r.h.s. of (1) is modeled as polynomial function of degree $n$. Then, (2) describes a model which is linear with respect to $n+2$ unknown parameters $a_{j}$, $j=0, \ldots, n+1$ :

$$
g_{\mathrm{AG}}(t)=a_{0} \cdot \widetilde{g}_{\mathrm{SG}}(t)+\sum_{j=1}^{n+1} a_{\mathrm{j}} t^{j-1} .
$$

This general linear least squares problem can be solved by defining the merit function (e.g., [25])

$$
\chi^{2}=\sum_{i=1}^{N}\left[\frac{g_{\mathrm{AG}, i}-a_{0} \cdot \tilde{g}_{\mathrm{SG}, i}-\sum_{j=1}^{n+1} a_{j} t^{j-1}}{\sigma_{i}}\right]^{2},
$$

where $i$ stands for the $i$ th of in total $N$ AG-SG data pairs, and $\sigma_{i}$ denotes the standard deviation of $g_{\mathrm{AG}, i}$. 


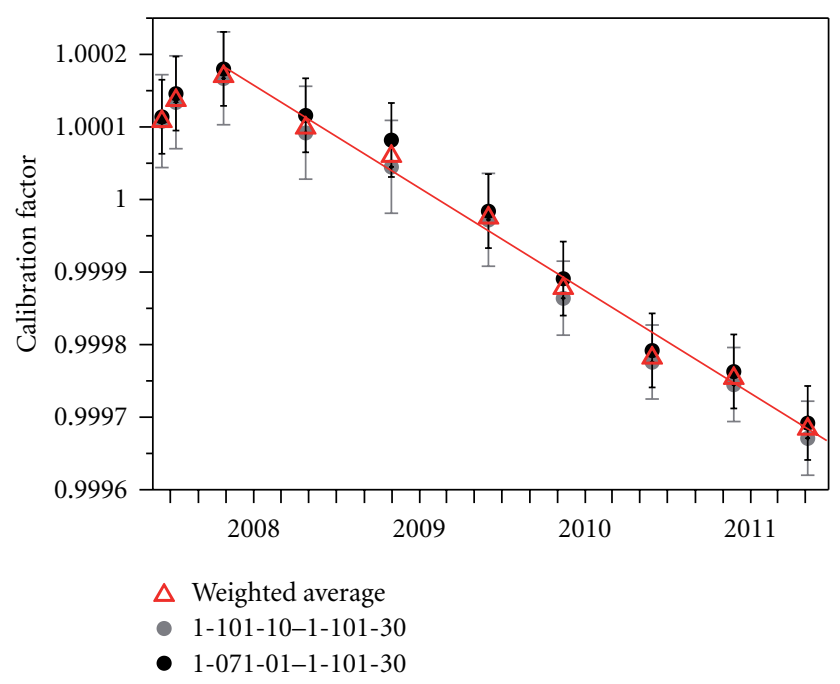

Figure 2: Scale factor determination of the Scintrex Autograv CG5, SN 40236. The grey and black dots refer to results taking only one specific gravity difference into account; the red triangles denote the results achieved by weighted averaging over all possible gravity differences along the Hochkar calibration line.

2.5. Accuracy Limit. The AG drop-to-drop scatter of free fall observations depends on the typical site noise and consequently limits the calibration accuracy. Depending on the microseismic activity, the standard deviation of the AG residual typically varies between 50 and $300 \mathrm{nms}^{-2}$. The large ground noise in Vienna (VI) hampers achieving a calibration accuracy better than $2 \%$ for a single experiment. However, getting a reliable calibration factor for the VI time series is crucial for comparing tidal analysis results. Even in case of random noise, the calibration factor does not necessarily converge or does not converge to the correct number even when a high amount of data pairs is available. This is shown by the following study.

We use synthetic body tides as reference and compare with an identical time series to which Gaussian noise has been added. The noise-standard deviation was defined by multiplying the AG drop set standard deviations taken from a real calibration experiment by the factors $0.1,1,3$, and 5 , resulting to a noise sigma between 10 and $600 \mathrm{nms}^{-2}$. 25 data sets with different random noise models have been compiled for each multiplication factor. Similarly as in the calibration experiments, the 3 sigma criterion has been applied to remove outliers before the linear adjustment. Figure 3(a) demonstrates that the correct factor (deviation $<0.2 \%$ o) is obtained only when the noise level is very low (e.g., about $10 \mathrm{nms}^{-2}$ ). With higher noise standard deviation, the regression factor generally converges after 10000 to 20000 data pairs, that is, 5 to 7 days of observation are required. This exactly confirms the result reported by $[5,7]$. However, the convergence level can deviate from the expected one by up to $1 \%$.

This behavior is due to the fact, that the even rather large number of data pairs still violates the "law of large numbers" principle of statistics. Consequently, it obviously happens in some cases, that the noise is weakly correlated with the tidal signal. The error range (maximum of the absolute deviation from expectation) increases almost linearly with the noise standard deviation (Figure 3(b)). It has to be pointed out, that the noise standard deviation of all models applied here does not vary with time like at sites where industrial or traffic noise causes typical day-night cycles in the noise amplitude. Of course, nonrandom noise deteriorates the calibration result further.

\section{Calibration Results}

3.1. SG/AG Comparison. Absolute gravimeters are obviously not free from systematic errors due to instrumental reasons. The drop set results generally should be randomly distributed, but often a systematic trend is visible in the residuals obtained by subtracting the tides and atmospheric effects while almost no trend is detectable in the SG record. Figure 4 presents typical examples of calibration experiments performed with SG GWR C025 and JILAg or FG5 type absolute gravimeters in December 2008 and June 2011, respectively, at Conrad observatory. During the December 2008 experiment, about 20000 single drops have been observed within a 5 days' interval, while for the June 2011 experiment about 23800 single drops gathered in 219 sets during 8 days could be evaluated. In both cases, the SG residual shows very small variation, while a distinct, predominantly linear drift is superposed to the AG residual. The observed AG trend is most likely of instrumental origin. At CO, the estimates presented in Table 1 indicate that both sensors experience almost the same hydrological signal. Additionally, there was no precipitation event during both calibration experiments.

Drift effects like those presented in Figure 4 have to be considered in the linear adjustment procedure. Otherwise the calibration factor might be systematically affected. Figure 5 shows the linear adjustment result of the experiments shown in Figure 4 for different drift models and in dependence on the number of data pairs used. If the AG drift signal is neglected, the calibration factor does not converge but oscillates around a certain level (black lines in Figure 5(a)). Additionally, the calibration factor strongly depends on the number of data pairs used. This effect is remarkably reduced when a linear drift is adjusted together with the calibration factor (red lines in Figure 5(a)). It is also important to note, that the level to which the calibration factors converge can differ by more than $1 \%$ from the result obtained by zero drift assumption. The application of the linear drift model actually improves the root mean square error of the adjustment slightly (Figure 5(b), upper and lower panel) while higher degree polynomials do not provide further error reduction. The calibration factor varies with the polynomial degree and only sometimes exceeds the $1 \%$ error range (grey box in Figure 5(b)). Besides, it is worth mentioning that the calibration results do not depend on the processing method (single drop versus set mean) with except of the standard deviation estimate. 


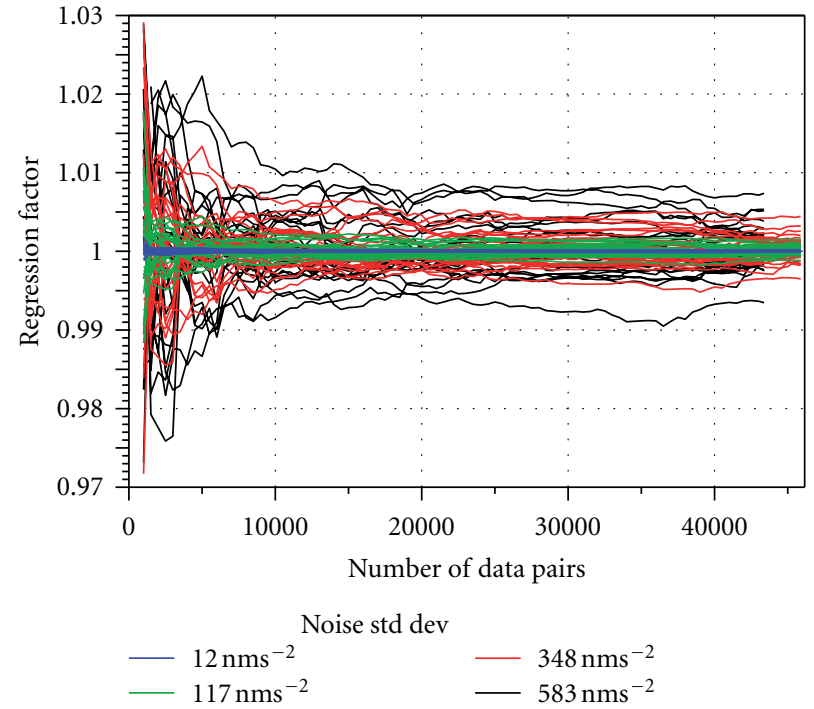

(a)

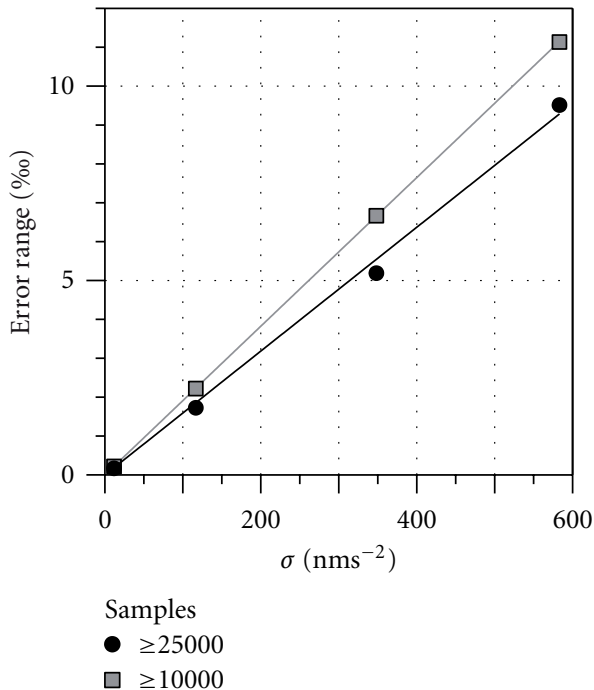

(b)

FIgURE 3: (a) Regression factor for synthetic data sets which combine synthetic tides without and with random noise of different standard deviation. For each noise-standard deviation, 25 data sets have been compiled. Without noise, the regression factor would be equal to 1 as expected. This is not shown on the view graph for simplicity. (b) Maximum deviation of the resulting regression coefficients from the value expected for noise-free data in dependence on the noise-standard deviation and on the number of data pairs entering the adjustment.

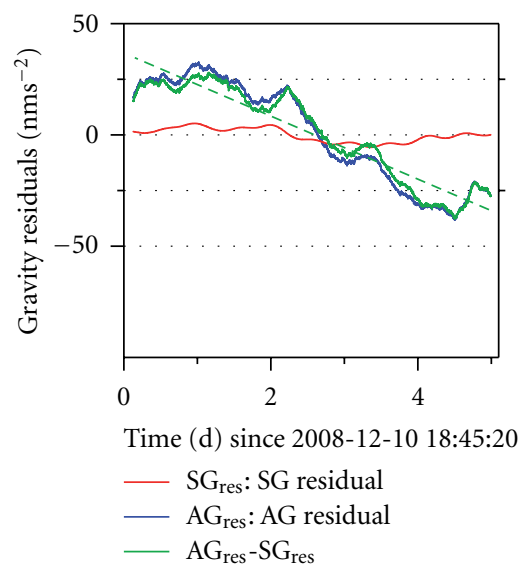

(a)

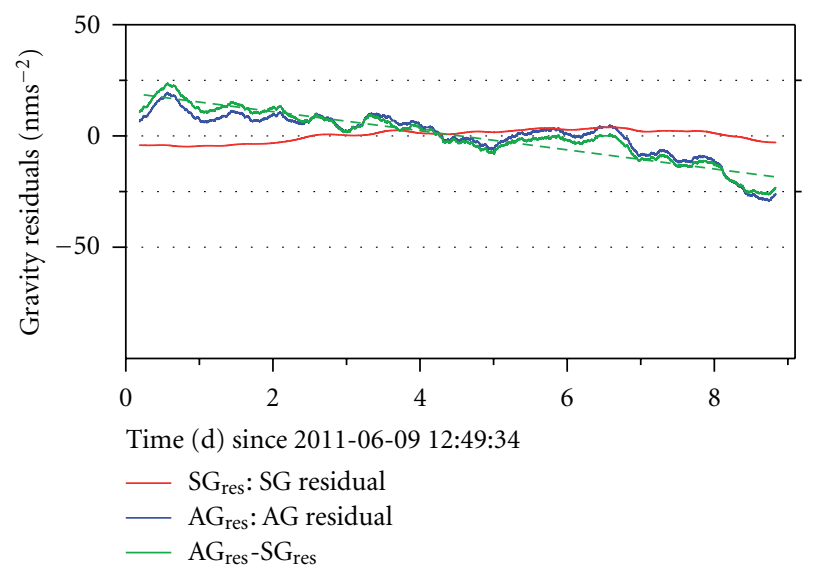

(b)

FIGURE 4: Gravity residual (running average) of SG (red) and AG (blue) during the calibration experiment at Conrad observatory in December 2008 (GWR C025/JILAg-6, (a)) and in June 2011 (GWR C025/FG5 242, (b)). The difference (green) is used to model the drift (dashed line).

3.2. SG/Spring Meter Comparison. The situation is completely different for spring gravimeters because of their much stronger and irregular drift, which cannot be approximated simply by linear functions. In the following the calibration experiment performed at Conrad observatory between July 13, 2010 and September 22, 2010 is discussed, when the SG GWR C025 monitored site by site with a Scintrex Autograv CG5. Figure 6 displays the calibration results that again depend on the adjusted drift model and on the number of data pairs taken into account. If higher degree drift polynomials are adjusted, the calibration factors converge faster, and differ by less than $0.1 \%$ o (Figure 6(a)). However, a period as long as more than 1 month is required to achieve convergence. The root mean square error of the residuals obtained from (2) after the adjustment decreases remarkably with increasing polynomial degree and remains constant beyond a certain polynomial degree (Figure 6(b)). The same holds for the calibration factor which gets stable beyond the same polynomial degree. This finding as well as inspecting the gravity residuals has been used as criterion for selecting the appropriate drift model.

Since the SG GWRC025 has been operating in VI and $\mathrm{CO}$, numerous calibration experiments have been performed, involving JILAg and FG5 absolute gravimeters as 

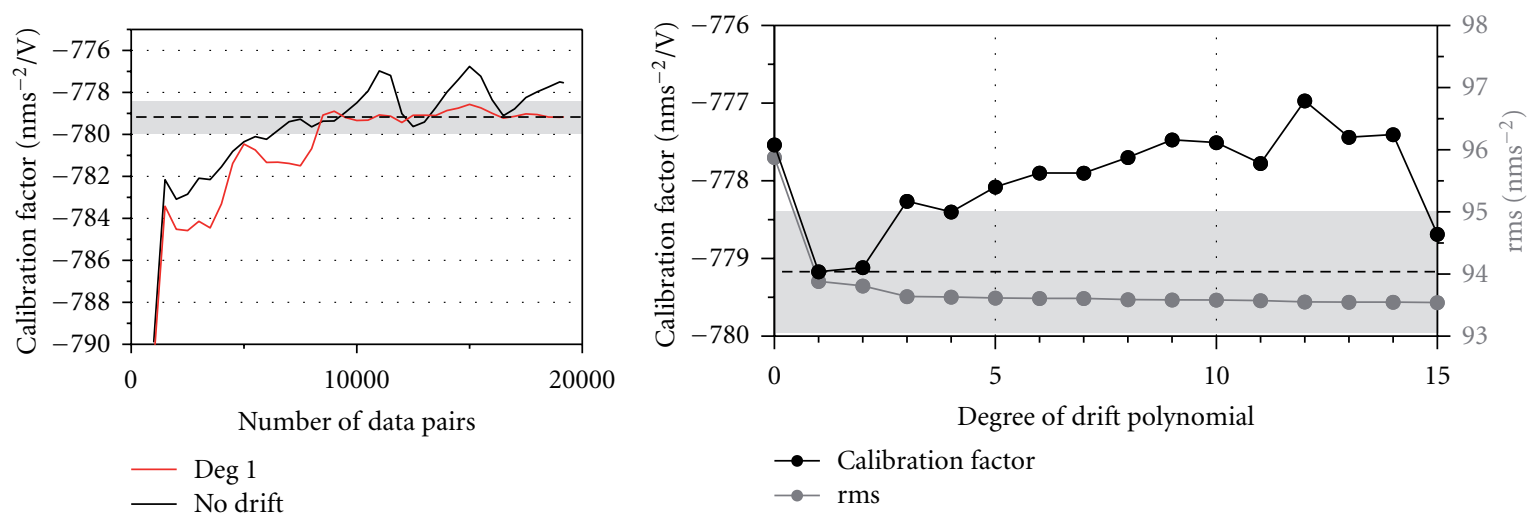

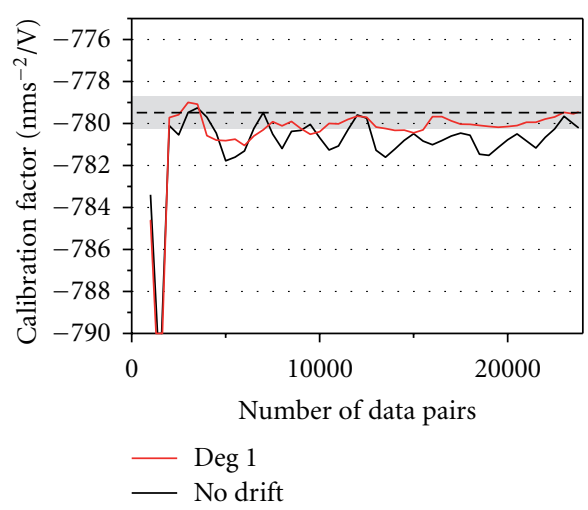

(a)

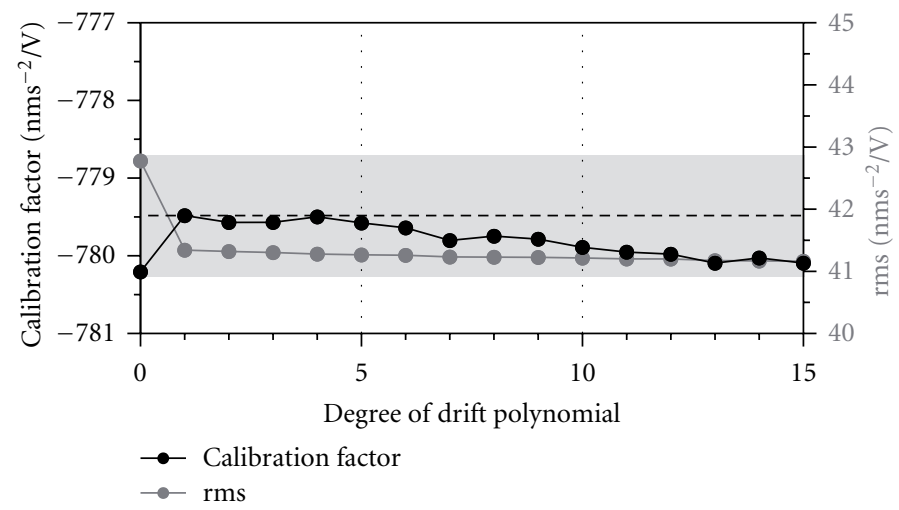

(b)

Figure 5: SG/AG comparison experiment at Conrad observatory in December 2008 (upper panels) and June 2011 (lower panels). (a) Calibration factor plotted against the number of data pairs used in the linear adjustment. No (black) or linear (red) drift has been adjusted. (b) Calibration factor (black) and RMS of the residual (grey) plotted against the polynomial degree selected for AG drift adjustment. The $\pm 1 \%$ error range is displayed as grey box.

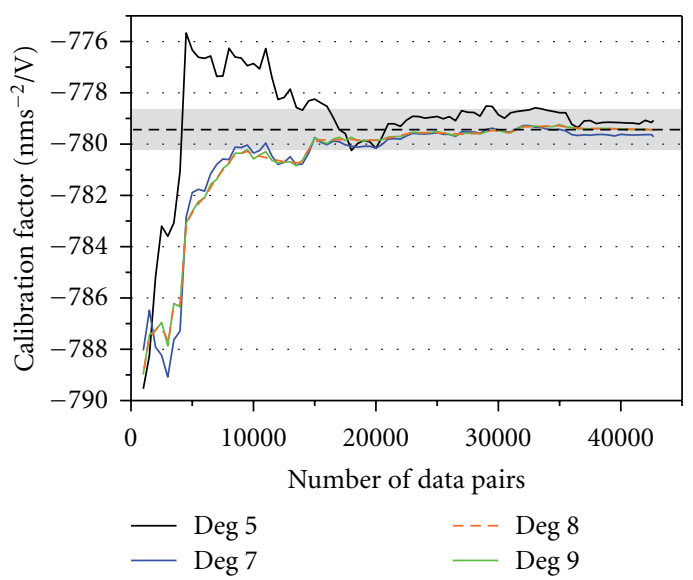

(a)

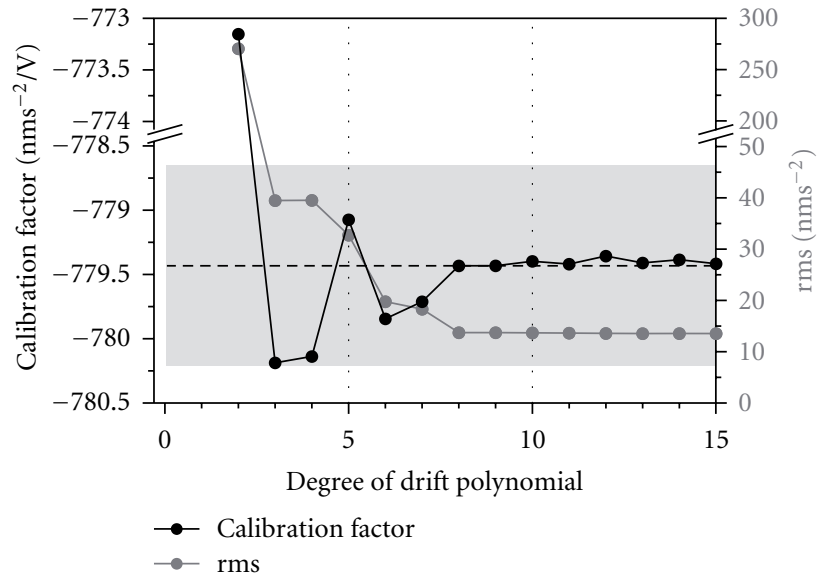

(b)

FIGURE 6: SG/CG5 comparison experiment at Conrad observatory (July 13, 2010 to September 22, 2010). (a) Calibration factor plotted against the number of data pairs used in the adjustment and for different drift polynomials. As best choice, a drift polynomial of degree 8 has been selected (dashed red line). (b) Calibration factor (black) and RMS of the residual (grey) plotted against the polynomial degree selected for AG drift adjustment. The $\pm 1 \%$ error range is displayed as grey box. 


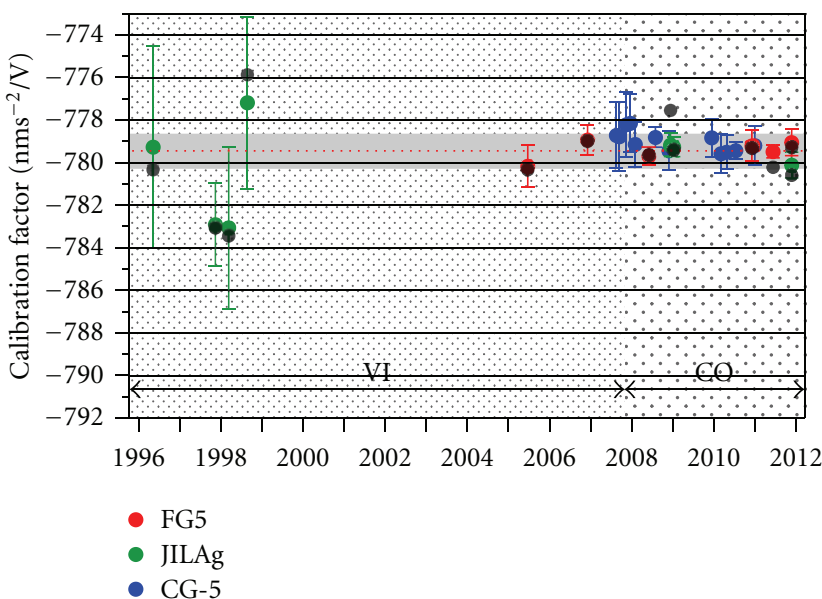

(a)

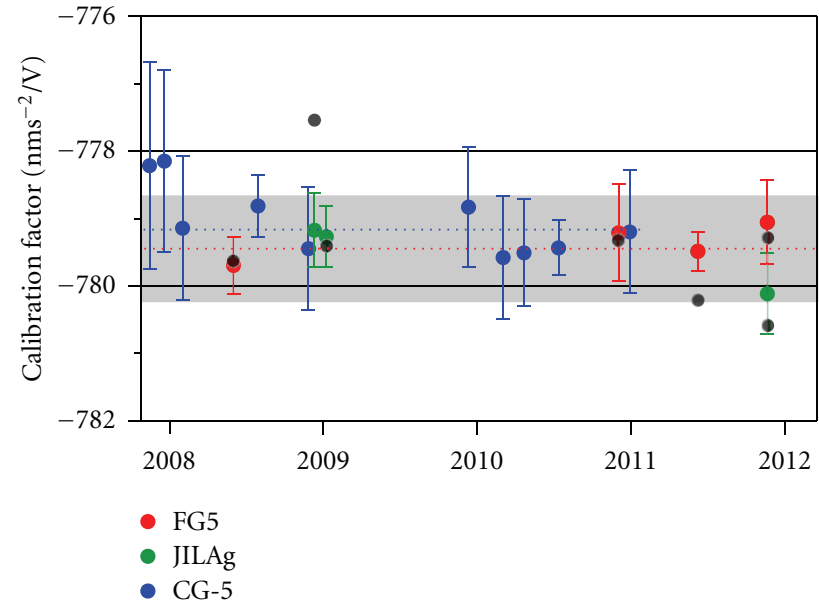

(b)

FIGURE 7: Calibration factors determined by adjusting colocated gravity observations with SG GWR C025 and FG5 (red dots), JILAg-6 (green dots), and Scintrex Autograv CG5 SN 40236 (blue dots). The differential drift of the reference gravimeter has been adjusted by polynomial functions. Dark grey dots indicate the results obtained for the zero drift assumption. The $\pm 1 \%$ o error range is displayed as grey box. The dotted lines indicate the calibration factors resulting from the CG5 $\left(-779.1628 \mathrm{nms}^{-2} / \mathrm{V}\right.$, blue $)$ and AG $\left(-779.4732 \mathrm{nms} \mathrm{s}^{-2} / \mathrm{V}\right.$, red) experiments. (a) All calibration experiments performed in Vienna (VI) and Conrad observatory (CO). (b) Zoom of the experiments performed at Conrad observatory $(\mathrm{CO})$.

well as the Scintrex Autograv CG5 SN 40236. All results are presented in Figure 7. With the exception of the JILAg-6 in VI and the first two CG5 experiments at CO, all calibration factors plot within the range of $\pm 1 \%$, provided the $A G$ drift is properly adjusted. The scatter increases considerably if zero drift is adopted (dark grey dots in Figure 7) while the mean calibration factor does not significantly change as long as a sufficiently large set of experiments is available. Due to the high noise level at the VI station the calibration experiments using the JILAg type absolute gravimeter are much less accurate than those using FG5s in 2005 and 2006. Under low noise level conditions like at CO, both AG types provide a comparable accuracy. Tables 2 and 3 compare the calibration results of the experiments performed in Vienna and at Conrad observatory with respect to the applied processing methods.

Both tables present the weighted average of the calibration factor $\bar{a}_{0}$ obtained by applying different processing methods, its error $e$ and the rms deviation $r$ of the single results from the average by using (4):

$$
\begin{aligned}
& \bar{a}_{0}=\frac{\sum_{i=1}^{M} W_{i} a_{0, i}}{\sum_{i=1}^{M} W_{i}}, \quad W_{i}=\frac{1}{\widetilde{\sigma}_{i}^{2}}, \\
& e=\sqrt{\frac{1}{\sum_{i=1}^{M} W_{i}}}, \quad r=\sqrt{\frac{\sum_{i=1}^{M}\left(a_{0, i}-\bar{a}_{0}\right)^{2}}{M-1}},
\end{aligned}
$$

where $\tilde{\sigma}_{i}$ is the standard deviation of the $i$ th of $M$ calibration experiments.

The difference between the mean calibration factors obtained with and without common AG drift adjustment amounts to about $0.6 \%$ at CO. Also the rms deviation $r$, which characterizes the scatter of single calibration results with respect to the average $\bar{a}_{0}$, is reduced by a factor of 3 when the AG drift is properly adjusted together with the calibration factor. The error $e$ reflects the accuracy, which is presently achievable with FG5 absolute gravimeters, as $\tilde{\sigma}$ strongly depends on the drop-to-drop scatter. The difference between the mean calibration factor obtained when AG drift is or is not taken into account is in the same order of magnitude, that is, the improvement by a common drift adjustment is just at the error limit. Nevertheless, based on the results presented here, considering the AG drift is recommended. This is potentially more important in future provided further instrumental improvements reduce the AG drop-to-drop scatter, or even presently at stations with very low noise level. The mean calibration factors derived from different processing methods, which determine both calibration factor and AG drift in a common adjustment, differ by $0.05 \%$ o (CO).

The difference between the results (modified $Z$-score method) obtained in Vienna and at Conrad observatory is $0.22 \%$. This number is about 3 times smaller than the formal error of the weighted average in Vienna, that is, there is no statistically significant change of the calibration factor associated with the transfer of the SG from Vienna to Conrad observatory. This finding is even more convincingly confirmed by considering exclusively the experiments with FG5s involved. In this case, the weighted averages differ only by $0.16 \%$. Because of the large scatter of the experiments with JILAg type absolute gravimeters in Vienna, the final calibration factor for SG GWR C025 is calculated taking into account only the FG5 experiments in Vienna and all FG5 and JILAg experiments at Conrad observatory, respectively. The final result is compiled in Table 3.

The results obtained by colocated observation with the Scintrex Autograv CG5 SN 40236 fit very well to those obtained by AGs (difference: $0.38 \%$ ). In particular, they do 
TABLE 2: Weighted average $\bar{a}_{0}$ of the calibration factor obtained by the calibration experiments in Vienna between 1996 and 2007 and at Conrad observatory between 2008 and 2012. Equation (4) was applied for calculations.

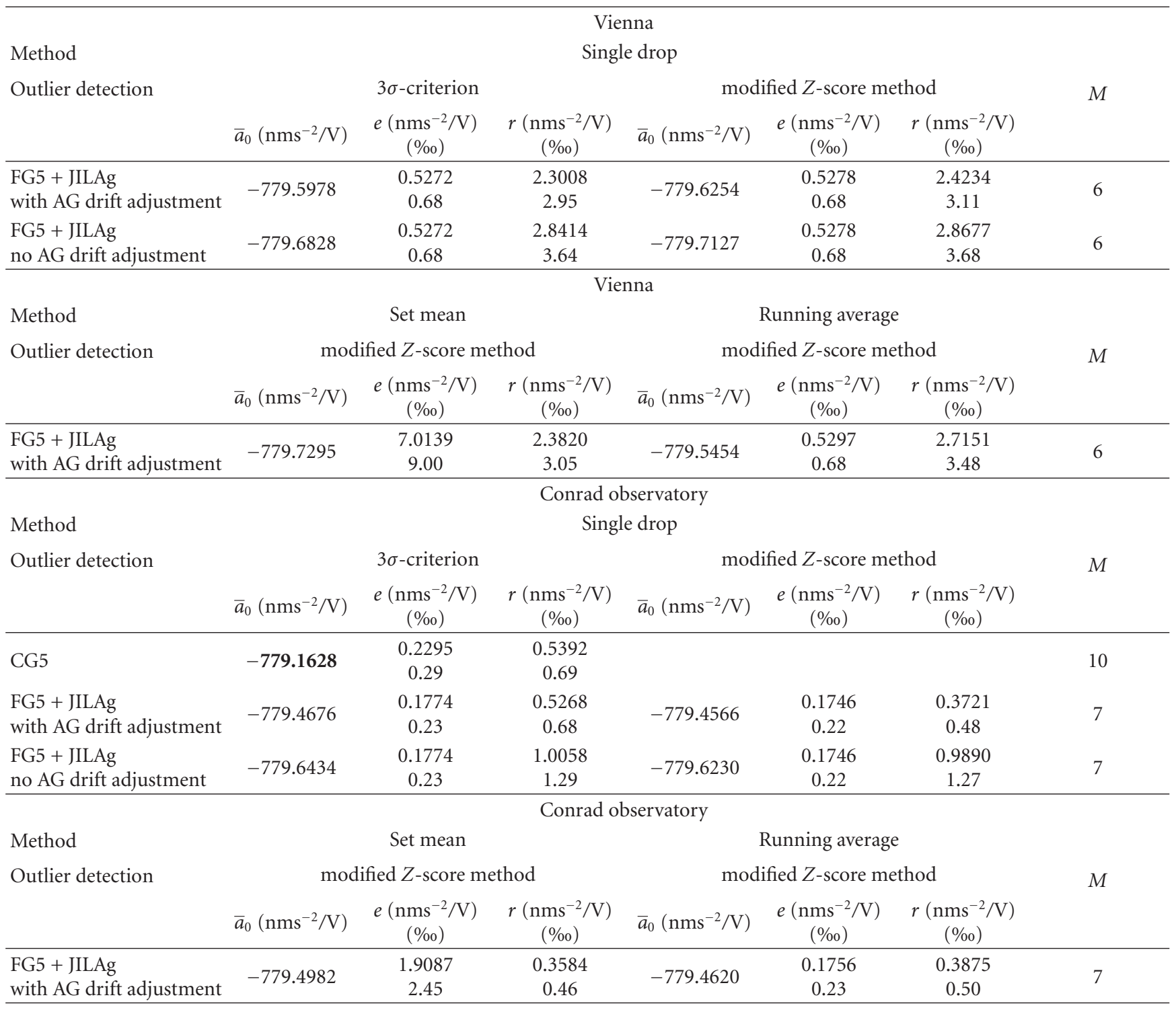

TABLE 3: Weighted average $\bar{a}_{0}$ of the calibration factor obtained by the calibration experiments in Vienna and at Conrad observatory between 2005 and 2012. Equation (4) was applied for calculations.

$$
\mathrm{VI}+\mathrm{CO}
$$

Method

Single drop

Outlier detection

$3 \sigma$-criterion

modified $Z$-score method

M $\bar{a}_{0}\left(\mathrm{nms}^{-2} / \mathrm{V}\right) \quad e\left(\begin{array}{ccccc}\left(\mathrm{nms}^{-2} / \mathrm{V}\right) & r\left(\mathrm{nms}^{-2} / \mathrm{V}\right) & \bar{a}_{0}\left(\mathrm{nms}^{-2} / \mathrm{V}\right) & e\left(\mathrm{nms}^{-2} / \mathrm{V}\right) & r\left(\mathrm{nms}^{-2} / \mathrm{V}\right)\end{array}\right.$

\begin{tabular}{|c|c|c|c|c|c|c|c|}
\hline & & & 700) & & (700) & (700) & \\
\hline $\begin{array}{l}\text { FG5 + JILAg since } 2005 \\
\text { with AG drift adjustment }\end{array}$ & -779.4537 & $\begin{array}{c}0.1692 \\
0.22\end{array}$ & $\begin{array}{c}0.5432 \\
0.70\end{array}$ & -779.4458 & $\begin{array}{c}0.1667 \\
0.21\end{array}$ & $\begin{array}{c}0.4476 \\
0.57\end{array}$ & 9 \\
\hline $\begin{array}{l}\text { FG5 + JILAg since } 2005 \\
\text { no AG drift adjustment }\end{array}$ & -779.6221 & $\begin{array}{c}0.1692 \\
0.22\end{array}$ & $\begin{array}{c}0.9255 \\
1.19\end{array}$ & -779.6055 & $\begin{array}{c}0.1667 \\
0.21\end{array}$ & $\begin{array}{c}0.9161 \\
1.18\end{array}$ & 9 \\
\hline
\end{tabular}


Table 4: Time lag of the SG GWR C025 at stations VI and CO.

\begin{tabular}{|c|c|c|c|c|c|}
\hline Site & & & & & $\mathrm{CO}$ \\
\hline Date & 199508 & 199709 & 199912 & 200404 & 200711 \\
\hline Time lag (s) & 16.995 & 9.345 & 10.040 & 9.131 & 8.702 \\
\hline Error $(\mathrm{s})$ & 0.005 & 0.027 & 0.047 & 0.066 & 0.026 \\
\hline
\end{tabular}

not indicate a significant change of the calibration factor, which might be caused by the transfer from VI to CO. The result shows also, that even spring gravimeters can support valuable information on the SG calibration factor provided they are carefully calibrated and their irregular drift is properly modeled in the adjustment process.

The SG phase calibration has been performed by applying the step response method [26]. The time lag has changed several times due to hard- and software upgrades. The results are presented in Table 4 . The formal errors indicate that the error of the tidal phases caused by erroneous time lag determination is expected to be less than $0.0006^{\circ}$ for semidiurnal and $0.0003^{\circ}$ for diurnal waves.

\section{Tidal Analysis}

Before tidal analysis, spikes and short-term disturbances present in the $1 \mathrm{~Hz}$ raw SG data (e.g., due to earthquakes or maintenance) were carefully removed by applying the software packages ETERNA v3.4 [27] and TSOFT [28]. Offsets due to technical reasons or maintenance have been corrected individually. ETERNA v3.4 [27] has also been applied for tidal analyses taking Tamura's [29] tidal potential into account. Ocean loading corrections have been performed based on load vectors provided by [13] for 7 different ocean models.

Table 5 shows the corrected tidal parameters for $\mathrm{O}_{1}$ and $\mathrm{M}_{2}$. The corrected amplitude factors at both sites differ by $0.04 \% 0\left(\mathrm{O}_{1}\right)$ and $0.08 \% 0\left(\mathrm{M}_{2}\right)$ only and do also confirm that the calibration factor did not significantly change during the transport of the SG from VI to CO. As both stations lie close together, the amplitude factor corrections for ocean loading are almost identical. Actually, the agreement between the amplitude factors gets slightly worse, while the phases come closer together after the ocean load correction. Interestingly, the differences of the phases in VI and CO are about $-0.006^{\circ}$ for both main tidal waves while the phases itself range between $-0.015^{\circ}$ and $+0.023^{\circ}$. This is two orders of magnitude higher than the formal errors of the phase lag determination. The averaged amplitude factors (VI, CO) for $\mathrm{O}_{1}, \mathrm{~K}_{1}$, and $\mathrm{M}_{2}$ are in full agreement with the numbers obtained for the West European network (WEN) [14, 15].

The averaged amplitude factors rather fit better to the nonhydrostatic models DDW/NHi [2] or MAT01/NH [3] with slight preference to the latter. The deviation from the inelastic DDW [2] model is about $0.8 \%$ o $\left(\mathrm{O}_{1}\right), 0.5 \%$ o $\left(\mathrm{K}_{1}\right)$ and $0.1 \% \circ\left(\mathrm{M}_{2}\right)$, respectively. The corresponding numbers for the MAT01/NH model [3] are $0.5 \% 0\left(\mathrm{O}_{1}\right), 0.2 \%$ o $\left(\mathrm{K}_{1}\right)$, and $0.4 \% 0\left(\mathrm{M}_{2}\right)$ (Table 6).

\section{Temporal Stability of the Calibration Factor}

The scatter of the calibration factors derived from single experiments (Figure 7) does not permit studying the temporal stability of the SG calibration. Therefore the time series were separated into overlapping 1-year intervals, which then were subjected to tidal analysis. Figure 8(a) displays the results after applying the ocean load correction [13] based on the TPXO.7.2 model. Figure 8(a) also allows for direct comparison of the tidal parameter obtained from the VI and $\mathrm{CO}$ time series and presents additionally the air pressure to gravity admittance factor calculated in the diurnal and semidiurnal tidal frequency band.

The air pressure admittance factor is systematically higher at $\mathrm{CO}\left(-3.35 \mathrm{nms}^{-2} / \mathrm{hPa}\right)$ than in VI $\left(-3.54 \mathrm{nms}^{-2} / \mathrm{hPa}\right)$. Because the distance between both stations is small (about $60 \mathrm{~km}$ ), the deformation part is expected to be similar at both sites. However, the Newtonian part is different, as both stations are located in different altitudes (VI: $190 \mathrm{~m}, \mathrm{CO}: 1045 \mathrm{~m}$ ). The admittance factors differ by $0.19 \mathrm{nms}^{-2} / \mathrm{hPa}$ roughly. This number matches fairly well the Newtonian effect due to the elevation difference calculated in flat approximation for a hydrostatic atmosphere.

The amplitude factors of $\mathrm{O}_{1}$ and $\mathrm{M}_{2}$ do not vary consistently, that is, the correlation is not significant on the $95 \%$ confidence level. The overall variation is as small as less than $\pm 0.2 \%$. In contrast, the phases of $\mathrm{O}_{1}$ and $\mathrm{M}_{2}$ show a statistically significant correlation (Figure 8(b)). According to the slope of the regression line, the range of the $\mathrm{M}_{2}$ phase variation $\left(0.02^{\circ}\right)$ is twice that of the $\mathrm{O}_{1}$ phase variation, indicating a link to time with errors of up to $2.4 \mathrm{~s}$. As time keeping is based on GPS, this suggests instrumental time lag variations. However, only the main tidal constituents are considered here. Therefore, in order to study the temporal stability of the SG calibration factor, theoretical body tides have been calculated based on the individual tidal parameter sets obtained from the analysis of each 1-year interval. These synthetic time series are then adjusted to synthetic tides using tidal parameters obtained from the analysis of the entire observation period in VI and CO, respectively, (Figure 9).

By this way, time dependant regression factors and time lags are obtained that can be interpreted as temporal calibration factor variation provided the tidal parameters are assumed not to change with time. Of course, this is not necessarily a valid assumption. Figure 9 demonstrates that all variations generally are well below $\pm 0.1 \%$. Time lag variations turn out to be in the range of $\pm 1 \mathrm{~s}$ which corresponds to a phase variation of about $\pm 0.008^{\circ}$ for $\mathrm{M}_{2}$. A weakly significant anticorrelation (0.55) between calibration factor and time lag variations exists.

\section{Conclusions}

For spring type gravimeters it is mandatory to consider the irregular drift in the adjustment of the calibration factor. The calibration experiments performed in VI and CO show, that even the drift of the AG should be considered in a common adjustment of the calibration factor. Though the 
TABLE 5: Tidal analysis results of the VI and CO gravity time series corrected for ocean load based on load vectors provided by [13].

\begin{tabular}{|c|c|c|c|c|c|c|}
\hline \multirow{2}{*}{ Ocean model } & \multicolumn{2}{|c|}{$\mathrm{CO}$} & \multicolumn{2}{|c|}{ VI } & \multicolumn{2}{|c|}{ Difference CO-VI } \\
\hline & $\delta\left(\mathrm{O}_{1}\right)$ & $\kappa\left(\mathrm{O}_{1}\right)\left[{ }^{\circ}\right]$ & $\delta\left(\mathrm{O}_{1}\right)$ & $\kappa\left(\mathrm{O}_{1}\right)\left[{ }^{\circ}\right]$ & $\Delta \delta\left(\mathrm{O}_{1}\right)$ & $\Delta \kappa\left(\mathrm{O}_{1}\right)\left[^{\circ}\right]$ \\
\hline No corr. & $1.14981 \pm 0.00006$ & $\mathbf{0 . 1 0 8 9} \pm 0.0028$ & $1.14979 \pm 0.00003$ & $0.1158 \pm 0.0014$ & 0.00002 & -0.0069 \\
\hline CSR4.0 & 1.15319 & -0.0186 & 1.15315 & -0.0131 & 0.00004 & -0.0055 \\
\hline DTU10 & 1.15322 & -0.0217 & 1.15316 & -0.0149 & 0.00006 & -0.0068 \\
\hline EOT11a & 1.15330 & -0.0219 & 1.15324 & -0.0151 & 0.00006 & -0.0068 \\
\hline FES2004 & 1.15369 & -0.0040 & 1.15364 & 0.0029 & 0.00005 & -0.0069 \\
\hline GOT00.2 & 1.15341 & -0.0139 & 1.15338 & -0.0081 & 0.00003 & -0.0058 \\
\hline HAMTIDE & 1.15359 & -0.0120 & 1.15354 & -0.0054 & 0.00005 & -0.0066 \\
\hline TPXO.7.2 & 1.15347 & -0.0098 & 1.15343 & -0.0050 & 0.00004 & -0.0048 \\
\hline Ave & 1.15341 & -0.0146 & 1.15336 & -0.0084 & 0.00005 & -0.0062 \\
\hline Stddev & 0.00019 & 0.0066 & 0.00019 & 0.0066 & 0.00001 & 0.0008 \\
\hline Max-min & 0.00050 & 0.0179 & 0.00049 & 0.0180 & 0.00003 & 0.0021 \\
\hline \multirow{2}{*}{ Ocean model } & \multicolumn{2}{|c|}{$\mathrm{CO}$} & \multicolumn{2}{|c|}{ VI } & \multicolumn{2}{|c|}{ Difference CO-VI } \\
\hline & $\delta\left(\mathrm{M}_{2}\right)$ & $\kappa\left(\mathrm{M}_{2}\right)\left[{ }^{\circ}\right]$ & $\delta\left(\mathrm{M}_{2}\right)$ & $\kappa\left(\mathrm{M}_{2}\right)\left[{ }^{\circ}\right]$ & $\Delta \delta\left(\mathrm{M}_{2}\right)$ & $\Delta \kappa\left(\mathrm{M}_{2}\right)\left[^{\circ}\right]$ \\
\hline No corr. & $1.18351 \pm 0.00003$ & $1.1056 \pm 0.0012$ & $1.18345 \pm 0.00001$ & $1.0778 \pm 0.0007$ & 0.00006 & 0.0278 \\
\hline CSR4.0 & 1.16224 & 0.0256 & 1.16217 & 0.0334 & 0.00007 & -0.0078 \\
\hline DTU10 & 1.16193 & 0.0244 & 1.16187 & 0.0294 & 0.00006 & -0.0050 \\
\hline EOT11a & 1.16212 & 0.0074 & 1.16205 & 0.0123 & 0.00007 & -0.0049 \\
\hline FES2004 & 1.16310 & 0.0403 & 1.16301 & 0.0469 & 0.00009 & -0.0066 \\
\hline GOT00.2 & 1.16192 & 0.0125 & 1.16182 & 0.0194 & 0.00010 & -0.0069 \\
\hline HAMTIDE & 1.16206 & 0.0041 & 1.16195 & 0.0110 & 0.00011 & -0.0069 \\
\hline TPXO.7.2 & 1.16174 & 0.0030 & 1.16161 & 0.0128 & 0.00013 & -0.0098 \\
\hline Ave & 1.16216 & 0.0168 & 1.16207 & 0.0236 & 0.00009 & -0.0068 \\
\hline Stddev & 0.00045 & 0.0138 & 0.00045 & 0.0135 & 0.00003 & 0.0017 \\
\hline Max-min & 0.00136 & 0.0373 & 0.00140 & 0.0359 & 0.00007 & 0.0049 \\
\hline
\end{tabular}

TABLE 6: Comparison of the corrected amplitude factor (average over all ocean models applied at VI and CO) with the DDW [2] and MAT [3] body tide models. Deviations are calculated as observed minus model amplitude factors.

\begin{tabular}{lcccccccc}
\hline & DDW/H [2] & DDW/NHi [2] & MAT01/NH [3] & WEN [14, 15] & Ave (CO, VI) & Dev DDW/H & Dev DDW/NHi & Dev MAT01/NH \\
\hline$\delta\left(\mathrm{O}_{1}\right)$ & 1.1528 & 1.1543 & 1.1540 & 1.1534 & 1.1534 & 0.0006 & -0.0009 & -0.0006 \\
$\delta\left(\mathrm{K}_{1}\right)$ & 1.1324 & 1.1345 & 1.1349 & 1.1353 & 1.1351 & 0.0027 & 0.0006 & 0.0002 \\
$\delta\left(\mathrm{M}_{2}\right)$ & 1.1605 & 1.1620 & 1.1616 & 1.1621 & 1.1621 & 0.0016 & 0.0001 & 0.0005 \\
\hline
\end{tabular}

systematic effect is small, the root mean square error of the averaged calibration factor is essentially reduced. Calibration results are biased not only by drift effects, but also by even random noise which limits the accuracy of the calibration experiment. Therefore the calibration experiment should be repeated several times. Spring type gravimeters have some potential to contribute to the SG calibration factor determination provided the drift is carefully modeled, for example, by higher degree polynomial functions, and the spring gravimeter is accurately calibrated. The dependence of the root mean square error of the adjustment on the polynomial degree of the drift function may serve as selection criterion for an appropriate drift model.

The reanalysis of the calibration experiments performed in VI and CO proves that the calibration factor of GWR C025 remained unchanged during the transfer from VI to CO. The SG/CG5 experiments fully support this statement and turn out to be a valuable extension to the SG/AG comparisons. A final calibration factor has been calculated as weighted average over in total 9 JILAg and FG5 experiments. Based on the root mean square deviation from the average, the accuracy estimate amounts to $0.5 \%$, while the formal 

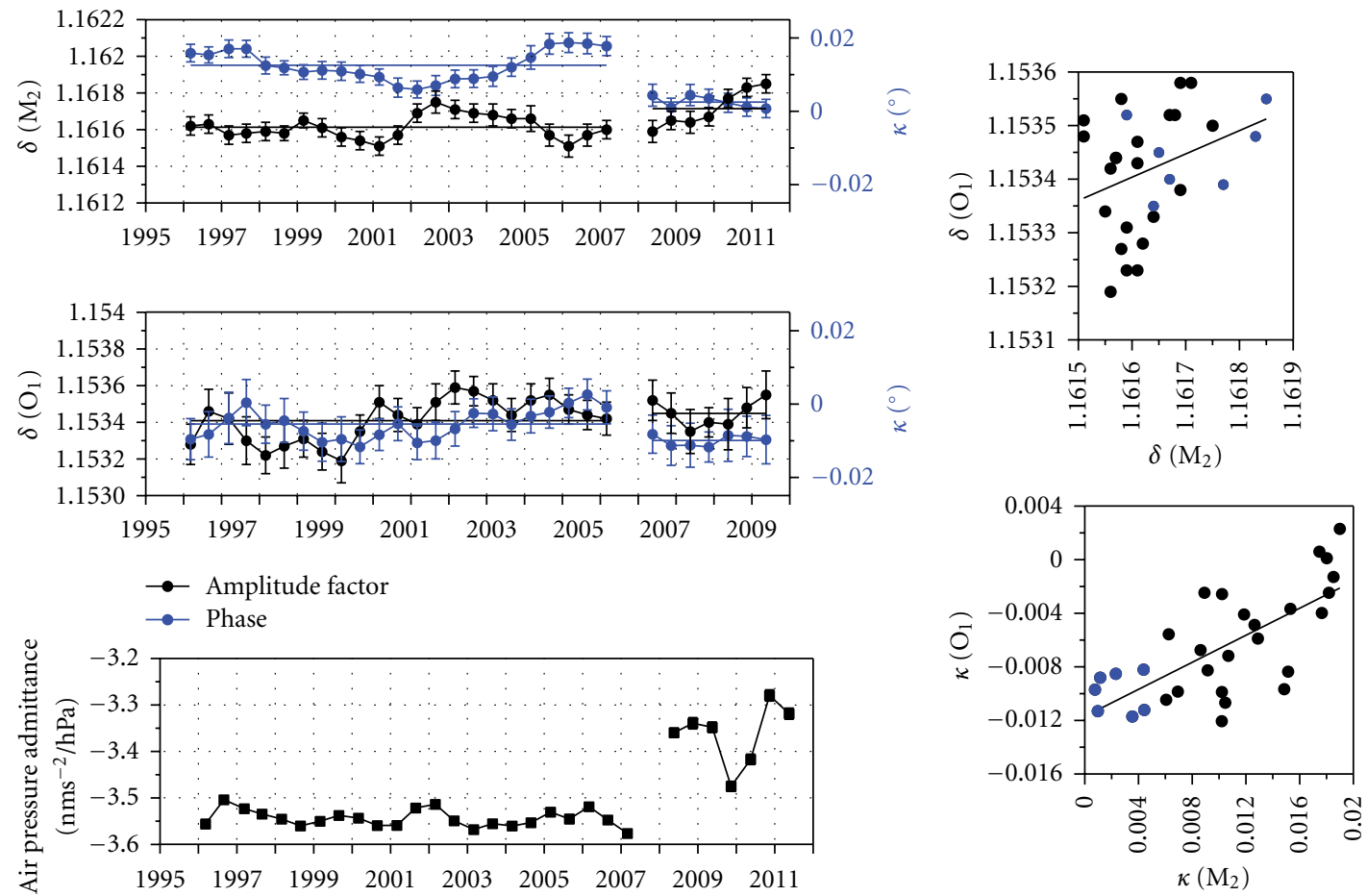

(a)

(b)

Figure 8: (a) Tidal analysis results from overlapping 1-year interval (black dots: amplitude factor, blue dots: phase). Ocean load correction [13] based on the TPXO.7.2 model has been applied. Horizontal lines indicate the analysis result obtained from the entire gravity time series.

(b) Correlation between the $\mathrm{O}_{1}$ and $\mathrm{M}_{2}$ tidal parameters. Only the phases are correlated significantly (black dots: VI, blue dots: CO).

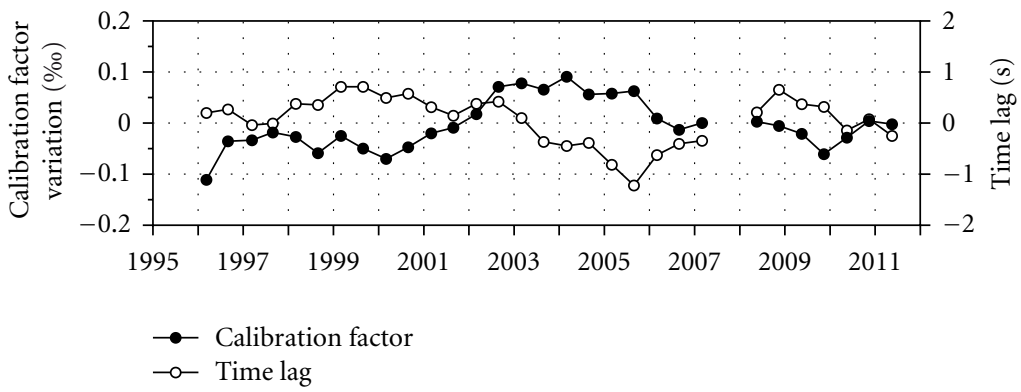

Figure 9: Temporal variation of the regression factor and the time lag obtained by adjusting synthetic tides based on tidal parameters obtained from 1-year interval analyses to synthetic body tides using tidal parameters obtained from analyzing the entire time series.

error of the calibration factor is even smaller $(0.2 \%)$. The calibration factor turns out to be temporarily stable. A regression analysis shows that temporal variations, if present, are below $\pm 0.1 \%$.

The reanalysis of the calibration experiments enables a direct comparison of the tidal parameters obtained in VI and CO. The amplitude factors $\mathrm{O}_{1}, \mathrm{~K}_{1}$, and $\mathrm{M}_{2}$ agree almost perfectly after correcting for ocean loading effects and fit closely to the nonhydrostatic body tide models calculated by $[2,3]$. The maximum deviation from the numbers provided by the nonhydrostatic DDW body tide model [2] is $0.8 \%$, the fit to MAT01/NH [3] is even smaller $(0.5 \%$ ). Additionally, the amplitude factors differ from the results of the West European network $[14,15]$ by less than $0.1 \%$.

\section{Acknowledgments}

Close cooperation with ZAMG (Austria), the owner of Conrad observatory, and the GWR C025, are gratefully acknowledged as well as all the efforts of the operators of the JILAg and FG5 absolute gravimeters D. Ruess, Ch. Ullrich (both BEV, Vienna), O. Francis (University of Luxembourg), and V. Pálinkás (Research Institute of Geodesy, Topography and Cartography, Department of Geodesy and Geodynamics). Two anonymous reviewers made valuable suggestions improving the paper. The author of the paper has no direct financial relations with the commercial identities mentioned in the paper that might lead to a conflict of interest for the author. 


\section{References}

[1] M. Van Camp and O. Francis, "Is the instrumental drift of superconducting gravimeters a linear or exponential function of time?" Journal of Geodesy, vol. 81, no. 5, pp. 337-344, 2007.

[2] V. Dehant, P. Defraigne, and J. M. Wahr, "Tides for a convective Earth," Journal of Geophysical Research B, vol. 104, no. 1, pp. 1035-1058, 1999.

[3] P. M. Mathews, "Love numbers and gravimetric factor for diurnal tides," Journal of the Geodetic Society of Japan, vol. 47, no. 1, pp. 253-259, 2001, in Proceedings of the 14th International Symposium on Earth Tides.

[4] J. Hinderer, N. Florsch, J. Makinen, H. Legros, and J. E. Faller, "On the calibration of a superconducting gravimeter using absolute gravity measurements," Geophysical Journal International, vol. 106, no. 2, pp. 491-497, 1991.

[5] O. Francis, T. M. Niebauer, G. Sasagawa, F. Klopping, and J. Gschwind, "Calibration of a superconducting gravimeter by comparison with an absolute gravimeter FG5 in Boulder," Geophysical Research Letters, vol. 25, no. 7, pp. 1075-1078, 1998.

[6] J. Hinderer, M. Amalvict, O. Francis, and J. Mäkinen, "On the calibration of superconducting gravimeters with the help of absolute gravity measurements," in Proceedings of the 13th International Symposium on Earth Tides, B. Ducarme and P. Pâquet, Eds., pp. 557-564, Brussels, Belgium, July 1997.

[7] O. Francis and T. Van Dam, "Evaluation of the precision of using absolute gravimeters to calibrate superconducting gravimeters," Metrologia, vol. 39, no. 5, pp. 485-488, 2002.

[8] B. Meurers, "Superconducting gravimetry in geophysical research today," Journal of the Geodetic Society of Japan, vol. 47, pp. 300-307, 2001.

[9] J. Hinderer, D. Crossley, and R. J. Warburton, "Gravimetric methods-superconducting gravity meters," in Treatise on Geophysics, G. Schubert and T. Herring, Eds., vol. 3, pp. 65122, Geodesy, 2009.

[10] S. Rosat, J. P. Boy, G. Ferhat et al., "Analysis of a 10-year (1997-2007) record of time-varying gravity in Strasbourg using absolute and superconducting gravimeters: new results on the calibration and comparison with GPS height changes and hydrology," Journal of Geodynamics, vol. 48, no. 3-5, pp. 360-365, 2009.

[11] U. Riccardi, S. Rosat, and J. Hinderer, "On the accuracy of the calibration of superconducting gravimeters using absolute and spring sensors: a critical comparison," Pure and Applied Geophysics, vol. 169, no. 8, pp. 1343-1356, 2012.

[12] O. Francis and M. Hendrickx, "Calibration of the LaCosteRomberg 906 by comparison with the superconducting gravimeter C021 in Membach (Belgium)," Journal of the Geodetic Society of Japan, vol. 47, no. 1, pp. 16-21, 2001.

[13] M. S. Bos and G. H. Scherneck, free ocean tide loading provider, http://froste.oso.chalmers.se/loading/.

[14] B. Ducarme, "Limitations of high precision tidal prediction," in Proceedings of the New Challenges in Earth Dynamics (ETS '08), Bulletin d'Informations Marées Terrestres, 145, pp. 11663-11677, 2009.

[15] B. Ducarme, S. Rosat, L. Vandercoilden, J. Q. Xu, and H. P. Sun, "European tidal gravity observations: comparison with earth tide models and estimation of the Free Core Nutation (FCN)," in Proceedings of the IAG General Assembly: Observing our Changing Earth, M. G. Sideris, Ed., vol. 133, pp. 523-532, International Association of Geodesy, Perugia, Italy, July 2007.
[16] B. Meurers, "Aspects of gravimeter calibration by time domain comparison of gravity records," Bulletin D'Informations Marées Terrestres, vol. 135, pp. 10643-10650, 2002.

[17] C. Kroner, "Hydrological signalsin the SG records at Moxa-a follow-up," Bulletin D'Informations Marées Terrestres, vol. 142, pp. 11353-11358, 2006.

[18] B. Meurers, M. Van Camp, and T. Petermans, "Correcting superconducting gravity time-series using rainfall modelling at the Vienna and Membach stations and application to Earth tide analysis," Journal of Geodesy, vol. 81, no. 11, pp. 703-712, 2007.

[19] Y. Imanishi, T. Higashi, and Y. Fukuda, "Calibration of the superconducting gravimeter T011 by parallel observation with the absolute gravimeter FG5 \#210-a Bayesian approach," Geophysical Journal International, vol. 151, no. 3, pp. 867-878, 2002.

[20] Y. Tamura, T. Sato, Y. Fukuda, and T. Higashi, "Scale factor calibration of a superconducting gravimeter at Esashi Station, Japan, using absolute gravity measurements," Journal of Geodesy, vol. 78, no. 7-8, pp. 481-488, 2005.

[21] B. Iglewicz and D. C. Hoaglin, "How to detect and handle outliers," in The ASQC Basic References in Quality Control: Statistical Techniques, E. F. Mykytka, Ed., vol. 16, American Society for Quality Control (ASQC), Statistics Division, ASQC Quality Press, Milwaukee, Wis, USA, 1993.

[22] B. Meurers and D. Ruess, "Errichtung einer neuen GravimeterEichlinie am Hochkar," Österreichische Zeitschrift für Vermessungswesen und Photogrammetrie und Photogrammetrie, vol. 73, no. 3, pp. 175-183, 1985.

[23] B. Meurers and D. Ruess, "Gravity measurements at the Hochkar calibration line (HCL)," Österreichische Beiträge zu Meteorologie und Geophysik, vol. 26, pp. 209-215, 2001, Proceedings of the 8th International Meeting on Alpine Gravimetry, Leoben, Austria, 2000.

[24] SCINTREX Limited, "CG5 Scintrex Autograv system operation manual," part \# 867700 Rev. 1, pp. 312, 2006.

[25] W. H. Press, S. A. Teukolsky, W. T. Vetterling, and B. P. Flannery, Numerical Recipes in Fortran, the Art of Scientific Computing, Cambridge University Press, Cambridge, Mass, USA, 2nd edition, 1992.

[26] H. G. Wenzel, "Precise instrumental phase lag determination by the step response method," Bulletin D'Informations Marées Terrestres, vol. 111, pp. 8032-8052, 1991.

[27] H. G. Wenzel, "The nanogal software: earth tide data processing package ETERNA 3.30," Bulletin D'Informations Marées Terrestres, vol. 124, pp. 9425-9439, 1996.

[28] M. Van Camp and P. Vauterin, "Tsoft: graphical and interactive software for the analysis of time series and Earth tides," Computers and Geosciences, vol. 31, no. 5, pp. 631-640, 2005.

[29] Y. Tamura, "A harmonic development of the tide-generating potential," Bulletin D'Informations Marées Terrestres, vol. 99, pp. 6813-6855, 1987. 

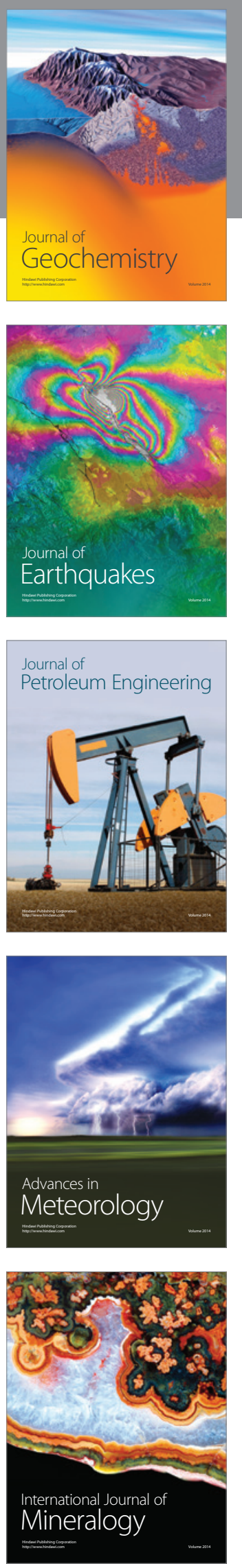
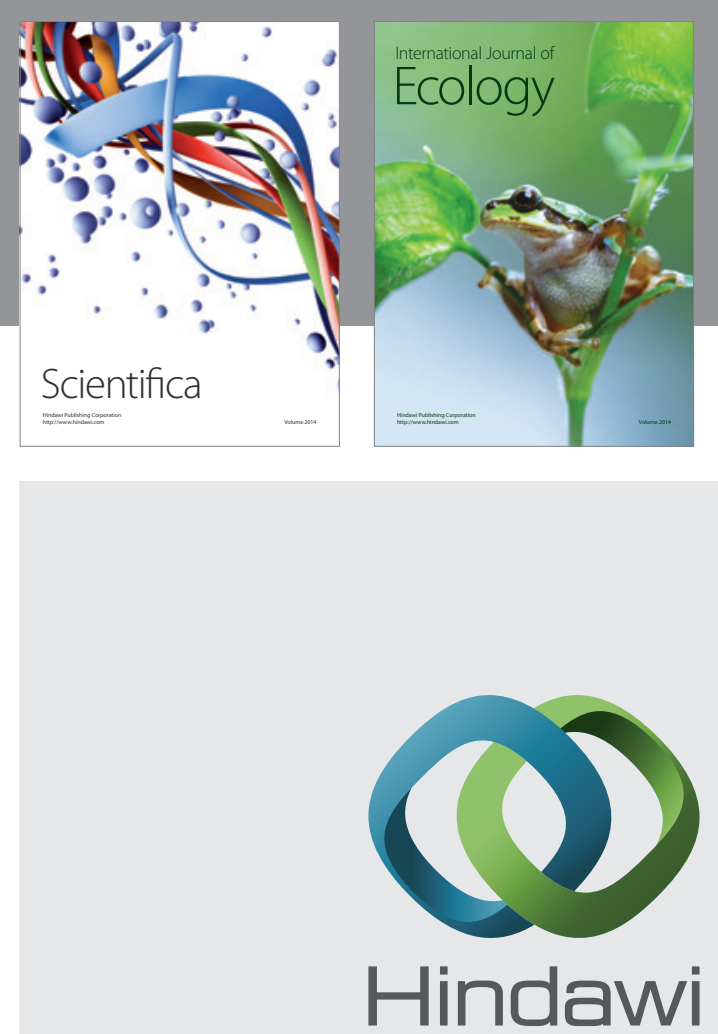

Submit your manuscripts at http://www.hindawi.com
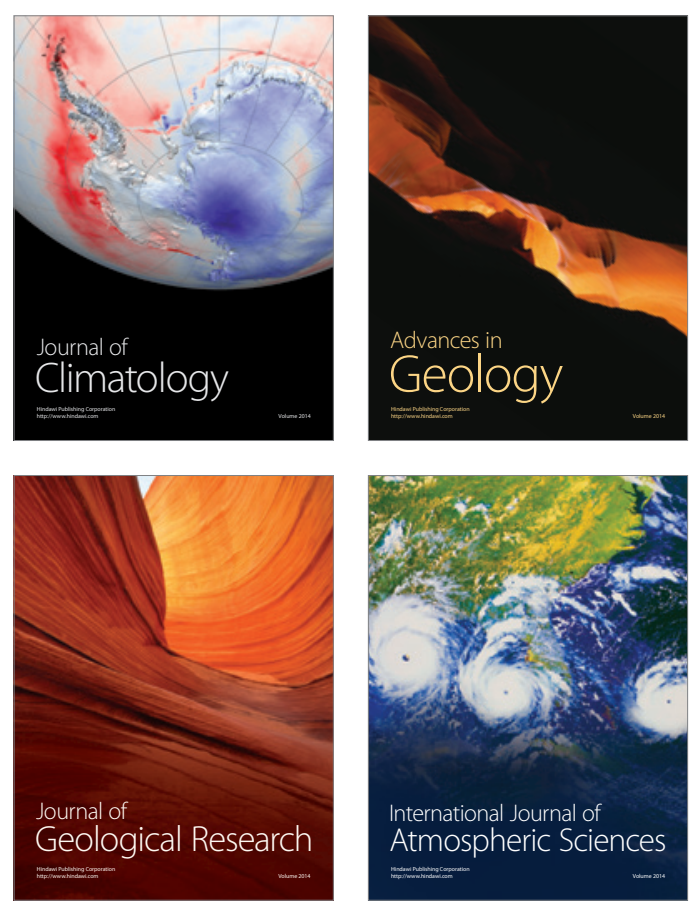
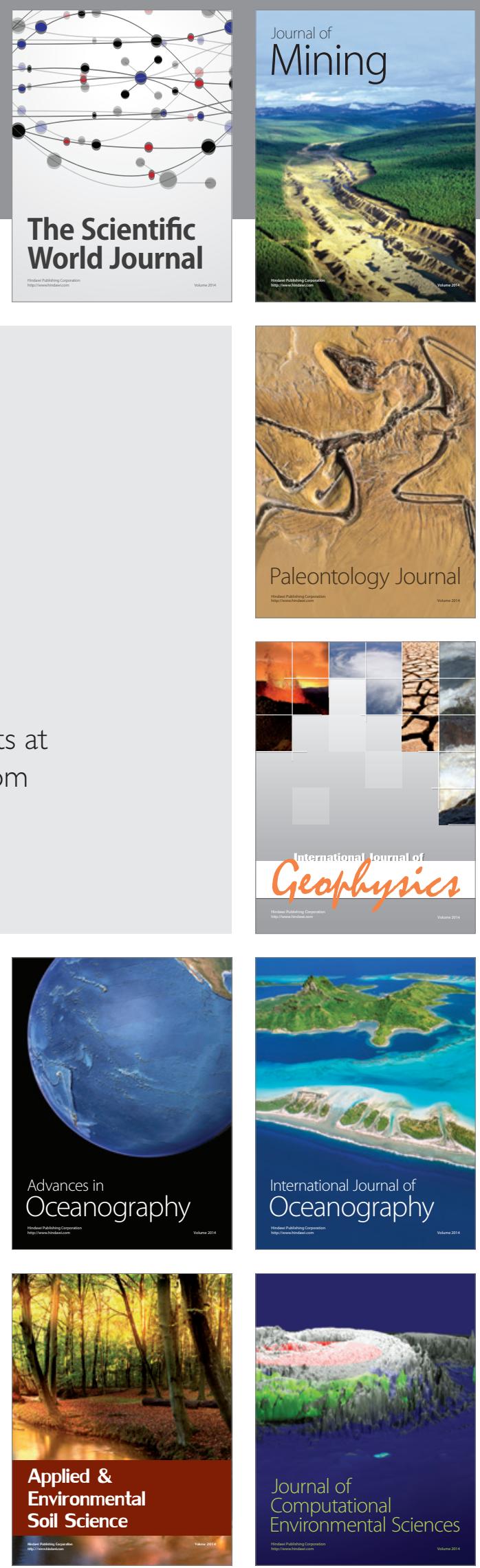